\title{
Pensar o gênero: diálogos com o Serviço Social
}

\section{Thinking gender: dialogues with Social Work}

\author{
Andrea Moraes Alves \\ Doutora em antropologia, professora associada da Escola de Serviço Social \\ da UFRJ, Rio de Janeiro, RJ, Brasil. andreamoraesalves@gmail.com
}

Resumo: $\mathrm{O}$ artigo apresenta as três abordagens sobre gênero mais comuns nas pesquisas no campo do Serviço Social brasileiro. São elas: o marxismo, as relações sociais de sexo e a interseccionalidade. Enquanto as duas primeiras são mais recorrentes, a última começa a adentrar as produções da área. $\mathrm{O}$ texto discute cada uma, mostra suas potencialidades e limites e estabelece algumas conexões entre elas. Por fim, aponta para lacunas presentes nas investigações sobre gênero no Serviço Social.

Palavras-chave: Gênero. Marxismo. Relações Sociais de Sexo. Interseccionalidade.
Abstract: The article presents the three most common approaches to gender in research in the field of Brazilian social service. They are: Marxism, social relations of sex and intersectionality. While the first two are more recurring, the latter begins to enter the productions of the area. The text discusses each of them, shows their potentialities and limits and establishes some connections between them. Lastly, it points to gaps in the investigation of gender in social work.

Keywords: Gender. Marxism. Social Relations of Sex. Intersectionality

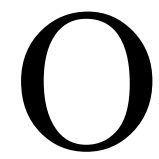

Serviço Social brasileiro produziu em sua história recente uma importante contribuição aos estudos no campo das relações de gênero. A discussão em torno da categoria gênero está presente nas pesquisas da área, e a intervenção profissional lida diretamente com as dimensões que envolvem o gênero, com especial destaque para os trabalhos sobre violência e direitos reprodutivos. Nos cursos de graduação, gênero está incluído seja em disciplinas obrigatórias, seja em eletivas. No Enade 2016, por exemplo, uma das questões abordava a Lei Maria da Penha. Nesse sentido, há um acúmulo consolidado de conhecimento sobre gênero no Serviço Social, movimento que 
acompanha a relevância que as relações de gênero têm para a compreensão da vida social.

Os sentidos dados a gênero no campo do Serviço Social são variáveis (e isso não é uma exclusividade da área). Gênero é um conceito em permanente disputa, para citarmos Joan Scott (2012). Seu significado nunca se estabiliza. Há no Serviço Social uma compreensão geral de que gênero trata das relações de poder na vida social, relações essas que atribuem posições assimétricas ao masculino e ao feminino. Desse modo, as desigualdades de gênero constituem-se como um dos focos do trabalho do assistente social e de suas preocupações de pesquisa. No entanto, o acordo parece parar nesse ponto. A partir desse caldo comum, emergem perspectivas distintas. Este artigo apresenta essas perspectivas.

Três advertências são necessárias aqui: em primeiro lugar, não há a pretensão de se esgotar todas as perspectivas presentes no campo; minha seleção é parcial. Essa parcialidade advém de minha experiência prática como docente de curso de graduação em Serviço Social. Em segundo lugar, sublinho que todas as perspectivas aqui apresentadas são igualmente relevantes, embora as duas primeiras (marxismo e as relações sociais de sexo) sejam as mais utilizadas e a última (interseccionalidade) esteja começando a adentrar nas produções acadêmicas em Serviço Social. Não há uma ordem de importância entre elas. A sistematização das perspectivas serve para começar um diálogo e não é, de maneira alguma, a palavra final sobre o tema. A terceira advertência é que podemos observar um trânsito entre perspectivas. Elas não se comportam necessariamente como estanques, mas dialogam entre si.

\section{Gênero e marxismo}

Para fins deste artigo, vou começar por me apoiar na leitura de Nancy Holmstrom em "Como Karl Marx pode contribuir para a compreensão do 
gênero?", publicado em português na coletânea Gênero nas Ciências Sociais" (2014). A autora defende que a abordagem de Marx oferece um caminho apropriado para a compreensão das relações de gênero como relações sociais. Para Marx, os seres humanos são intrinsecamente interdependentes, e a produção e reprodução da vida humana são, ao mesmo tempo, biológicas e sociais. As posições relacionais de homens e de mulheres são componentes da produção e da reprodução. Portanto, divisões que se apresentam como naturais são, não obstante, socialmente construídas. Esse é um ponto fundamental para qualquer teorização acerca das relações entre gêneros. Nesse sentido, Holmstrom está correta em ressaltar a contribuição inicial de Marx para pensar o tema. No entanto, acrescentaria que, para Marx, a divisão sexual do trabalho é entendida como interdependência entre os sexos, e não pensada em termos de subordinação de um sexo a outro. A problematização da divisão do trabalho em Marx começa com a separação entre trabalho manual e trabalho intelectual, e não com a divisão sexual. O fato de que mulheres na ordem capitalista irão compor a força de trabalho é tratado por Marx menos como uma questão que afeta as mulheres e mais como um processo que diz respeito à lógica da acumulação capitalista.

Coube ao trabalho de F. Engels, A origem da familia, da propriedade privada e do Estado (2014), publicado originalmente em 1884, o desenvolvimento de uma teoria que ligou as relações de dominação das mulheres pelos homens à formação da família monogâmica e ao advento da propriedade privada. Entre as diversas críticas que Engels sofreu, a fundamental incide sobre o fato de que sua explicação sobre a origem da subordinação das mulheres apresenta uma série de lacunas e imprecisões, deixando de fora que "a dominação masculina, às vezes violenta, existe também nas sociedades pré-classistas que não conhecem a propriedade privada" (Trat, 2014, p. 362). As críticas formuladas à obra de Engels serviram como ponto de partida para uma renovação da abordagem marxista no que tange ao lugar das mulheres. Nos anos 1970, esse debate frutificou no interior do feminismo dessa década. Não vamos recuperá-lo aqui, pois seria tema para outro artigo, mas apontamos a contribuição fundamental de uma autora brasileira que é referência até os 
dias de hoje dentro e fora do Serviço Social: Heleieth Saffioti. Ela será uma das pioneiras na revisão do tratamento dado à subordinação feminina nas sociedades de classes.

Duas questões paralelas atravessam a renovação da abordagem marxista sobre gênero. A primeira delas é desenvolver a reflexão sobre o que responde à alocação das mulheres no mundo da reprodução, visto como trabalho não pago, e dos homens ao lugar da produção, ou do trabalho assalariado. Em segundo lugar, responder à pergunta sobre qual é a participação do trabalho não pago das mulheres na reprodução da força de trabalho, elemento essencial à ordem capitalista. E mais: qual seria o impacto da incorporação das mulheres no mundo do trabalho assalariado? É necessário sublinhar que é prioritariamente a discussão sobre o lugar subordinado dado às mulheres na vida social que guia o olhar dos debates marxistas.

Saffioti escreveu uma tese de doutorado no ano de 1969 intitulada $A$ mulher na sociedade de classes: mito e realidade. É um trabalho de fôlego no qual a autora lida com uma questão: a tese de que a incorporação das mulheres à força de trabalho no capitalismo varia conforme o grau de desenvolvimento das forças produtivas. O pleno desenvolvimento do sistema capitalista de produção expele o trabalho feminino em um processo de marginalização das mulheres, levando-as ao trabalho parcial ou à posição exclusiva de "dona de casa". A figura da "dona de casa" de família de classe trabalhadora seria o produto mais acabado desse processo, pois, afastada do mundo produtivo ou parcialmente integrada a ele, a mulher ficaria relegada às tarefas da reprodução, aquelas que produzem e reproduzem as gerações atuais e futuras de trabalhadores assalariados. Nesse aspecto, as mudanças no lugar da mulher na família seriam essenciais para entender a sociedade capitalista. A autora conclui seu trabalho apresentando uma instigante discussão sobre a alienação da dona de casa.

Esse processo de marginalização da mulher é permeado pelo que Saffioti qualifica de "mística feminina", ${ }^{1}$ ou seja, a legitimação ideológica

1. Uma referência ao livro de Betty Friedan, A mística feminina, lançado em 1963. 
do lugar subalternizado da mulher na sociedade. Saffioti divide a tese em dois grandes momentos: um em que apresenta a ideia central de marginalização das mulheres na sociedade de classes e outro em que se dedica a acompanhar como se efetiva essa marginalização em uma sociedade periférica como a brasileira. A tese é um marco na produção intelectual de nosso país e nos apresenta a conexão entre sexo e classe social. Para ela, o sexo é uma característica da estratificação social. A estratificação é um princípio de classificação social que estabelece distâncias diferenciais e assimétricas entre posições. A estratificação distribui prestígio, status e autoridade na ordem social. Nessa qualidade é que se pode estabelecer um vínculo entre sexo e classe. A produção na sociedade de classes depende da formação de uma força de trabalho que inclui alguns elementos e segrega outros. Essa seleção, por sua vez, depende fundamentalmente das atribuições de status baseadas em sexo, idade e raça, ${ }^{2}$, na medida em que são esses os fatores que determinam quem ocupará lugares na produção e quem ficará subalternizado ou excluído nesse processo. Segundo a autora, a estratificação social é um catalisador das tensões sociais na ordem capitalista. Nesse sentido, as lutas feministas em torno do acesso das mulheres ao trabalho remunerado carregam um potencial revelador das contradições da própria formação capitalista. Esse potencial pode ser realizado na medida em que os limites da incorporação das mulheres ao mundo do trabalho assalariado e a natureza da relação entre reprodução (as tarefas domésticas) e o mundo da produção — a divisão sexual do trabalho - sejam efetivamente compreendidos. O desafio do feminismo

2. A raça perde força na análise de Saffioti, pois ela compartilha de uma leitura que vê a sociedade brasileira como um espaço de miscigenação, onde a cor poderia ser suavizada como atributo, sendo a figura do mulato um emblema dessa operação. Já o sexo não teria a mesma capacidade. Sendo assim, sexo ocuparia um lugar essencial como forma de estratificação social. Nas palavras da própria autora: “As características raciais visíveis do grupo minoritário, muitas vezes selecionadas socialmente como marcas negativas, a fim de tornar desigual a competição para os dois grupos raciais em presença, podem, portanto, perder-se através da miscigenação. No caso da mulher, o atributo isolado socialmente para operar como regulador da competição — o sexo - não pode nem ser atenuado nem desaparecer. Disto isto não se pode concluir que a estratificação a partir do sexo jamais desaparecerá da sociedade. A digressão tem o objetivo somente de diferenciar a situação da mulher da situação das minorias raciais e mostrar que o sexo, enquanto fator natural que é, estará sempre presente, podendo ser usado como critério de atribuição de status com consequências negativas para a mulher, como empiricamente se tem verificado" (Saffioti, 2013, p. 425). 
para Saffioti seria realizar essa compreensão e nessa tarefa incluir também os homens. "Sendo homens e mulheres seres complementares na produção e na reprodução da vida, fatos básicos da convivência social, nenhum fenômeno há que afete a um deixando de atingir o outro sexo" (Saffioti, 2013, p. 34).

A tese central de Saffioti, qual seja: a marginalização da força de trabalho das mulheres no capitalismo, foi revista por teóricas ligadas ao campo da sociologia do trabalho. Essa revisão foi de grande relevância para a consolidação desse campo de estudos no Brasil (Souza-Lobo, 2011). Atentou-se, sobretudo, para a investigação das relações de trabalho propriamente ditas e para a crescente heterogeneidade dos processos de trabalho no capitalismo. A expansão e a diversificação do emprego feminino em alguns setores produtivos na América Latina dos anos 1970 trouxeram a necessidade de reformulação da hipótese da marginalização ao mesmo tempo em que desafiaram as pesquisas a pensar o porquê de essa incorporação da força de trabalho das mulheres conviver com a permanência da subordinação social das mesmas, expressa nos baixos salários e na segregação ocupacional. As mulheres ampliaram sua participação na indústria e na agricultura, mas também cresceram o trabalho doméstico remunerado e o setor de serviços. A modernização tecnológica não afastou necessariamente as mulheres do trabalho assalariado, embora os salários delas sejam mais baixos em relação ao dos homens no mesmo tipo de função. Para além de pensar o sexo como mecanismo de estratificação social constitutivo da exploração capitalista, a sociologia do trabalho aprofundou-se na investigação da forma da divisão sexual do trabalho em sua variabilidade histórica e conjuntural. A chamada "sexualização das ocupações" passou a ocupar lugar de destaque na produção desse campo de estudos ao longo da década de 1980 e início da de 1990.

A pergunta sobre a construção das tradições que fixam o sexo do trabalho, das ocupações e das tarefas, remete, especialmente nas realidades heterogêneas da América Latina, à reconstituição tanto da história das trajetórias femininas e das tradições e representações simbólicas, como do comportamento do mercado de trabalho e da dinâmica das relações capitalistas. (Souza-Lobo, 2011, p. 172) 
Essas trajetórias, tradições e representações simbólicas têm um lugar distinto daquele atribuído por Saffioti à "mística feminina". ${ }^{3}$ Não são legitimações ideológicas, mas práticas sociais, ou seja, como homens e mulheres vivem as relações de trabalho, como experimentam situações determinadas no mercado de trabalho, como produzem resistências. Dá-se um lugar mais estruturante às relações de gênero no mundo do trabalho, tão relevante quanto a dinâmica do capital. Passa-se a prestar mais atenção à diversidade e à complexidade dos processos de trabalho e das relações no interior do mercado de trabalho, abrindo espaço para pesquisas que mapeiam as trajetórias laborais de homens e de mulheres, suas distintas relações com o sindicato, aproximando as investigações de preocupações com o tema das mobilidades no mundo do trabalho e das estratificações sexuais e ocupacionais. ${ }^{4}$

\section{As relações sociais de sexo}

A noção de que as relações de trabalho são sexuadas e portadoras de hierarquias de gênero é o ponto inicial para a compreensão da abordagem das "relações sociais de sexo". O termo relações sociais refere-se justamente a essa perspectiva estrutural das relações entre os sexos. A divisão entre homens

3. É importante lembrar que Saffioti escreveu outros trabalhos além da tese e que se dedicou posteriormente a refletir sobre o conceito de patriarcado e sua relação com a violência contra as mulheres, complexificando bastante sua análise anterior sobre a questão da ideologia, assim como das relações entre gênero, raça e classe. Em seus escritos posteriores, a autora aproxima-se da ideia de que gênero, raça e classe estão imbricados e são estruturantes da vida social. Nas palavras da autora: "O importante é analisar estas contradições na condição de fundidas ou enoveladas ou enlaçadas em um nó. Não se trata da figura do nó górdio ou apertado, mas do nó frouxo, deixando mobilidade para cada uma de seus componentes. Não que cada uma destas contradições atue livre e isoladamente. No nó, elas passam a apresentar uma dinâmica especial, própria do nó. Ou seja, a dinâmica de cada uma condiciona-se à nova realidade, presidida por uma lógica contraditória. De acordo com as circunstâncias históricas, cada uma das contradições integrantes do nó adquire relevos distintos. E esta motilidade é importante reter, a fim de não tomar nada como fixo, aí inclusa a organização destas subestruturas na estrutura global” (Saffioti, 2004, p. 125). Esta é uma posição diversa daquela apresentada em sua tese de 1969.

4. O que desliza o conceito de classe para uma interpretação de cunho mais weberiano. 
e mulheres e as atribuições de poder que repartem esses elementos de forma contraditória são constitutivas da vida social em geral. Que as relações de trabalho (contraditórias no capitalismo) sejam inerentemente sexuadas (e contraditórias) traduz justamente a percepção de que toda vida social o é. A noção de que sexo e classe (relações que se estabelecem na produção da vida material) são consubstanciais tem a ver justamente com essa compreensão de que são ambas constitutivas uma da outra, antagônicas e estruturantes da vida social. Vale ressaltar o caráter de antagonismo que essas relações têm. Segundo Kergoat (2016, p. 20): "Para que se possa falar em relação social, é necessário que esta domine, oprima e explore". Nesse sentido, o trabalho das mulheres é trabalho explorado e expropriado, na medida em que elas são força de trabalho disponível para o capital e que as tarefas destinadas à reprodução da própria força de trabalho como cozinhar, lavar, cuidar de crianças, são classificadas socialmente como femininas. A expropriação e a exploração das mulheres na divisão do trabalho sob o capitalismo deixam claro que a figura clássica do trabalhador livre não pode ser definida estritamente pelo masculino. Parafraseando o título do livro de Elisabeth Souza-Lobo (2011): "A classe operária tem dois sexos".

As políticas voltadas para a conciliação entre trabalho doméstico (trabalho reprodutivo) e trabalho assalariado (trabalho produtivo) incidem sobre as formas de inclusão da força de trabalho das mulheres no mundo produtivo e afetam as relações entre homens e mulheres no espaço doméstico (Hirata e Kergoat, 2007). Segundo Fraser (2009), uma das críticas centrais do feminismo liberal dos anos 1970 ao Estado de bem-estar baseou-se na denúncia do modelo do homem provedor como paradigma da família. Esse modelo contribuiu para o confinamento das mulheres ao mundo privado.

Na perspectiva das relações sociais de sexo, o conceito de trabalho passa a ser dilatado. O trabalho na sua acepção marxista clássica, entendido como produção de valor, é modificado e passa a referir-se ao que Kergoat (2016) chama de "produção do viver em sociedade" ou o conjunto das atividades necessárias para a produção material e reprodução da vida. Foi preciso pensar o trabalho a partir do mundo das mulheres para que a compreensão 
das relações sociais no capitalismo transbordasse a perspectiva clássica do trabalho como produção de valor, incluindo a reprodução dos seres humanos e sua socialização (a família) como esfera também produtiva - embora não produtora de mais-valia - , e não somente unidade de consumo. Nesse sentido, a perspectiva das relações sociais de sexo estabelece um diálogo com o marxismo, mantém sua perspectiva materialista, mas promove uma reinterpretação de conceitos-chave da tradição marxista, como trabalho, a relação entre produção e reprodução e classe social. Compreender esse salto interpretativo é fundamental para acompanharmos o debate como um todo.

O trabalho foi redefinido e mudou de estatuto: de uma simples produção de objetos, de bens, ele se transformou no que alguns chamam de produção do viver em sociedade [...] trabalhar é transformar a sociedade e a natureza e, no mesmo movimento, transformar-se a si mesmo. $\mathrm{O}$ trabalho torna-se assim uma atividade política. Nessa perspectiva feminista materialista, é a própria definição de trabalho que implode. (Kergoat, 2016, p. 18)

Autoras contemporâneas no campo marxista têm refletido sobre essa ressignificação do conceito de trabalho que implica uma rearticulação da relação entre produção e reprodução. Em vez dessas esferas serem pensadas como separadas e relacionais, passa-se a vê-las como acopladas uma à outra, como uma unidade. Se a reprodução era entendida como reposição da força de trabalho e assim necessária ao capital, nessa nova interpretação a reprodução social é tida como a esfera de "manutenção e reprodução da vida em nível diário e geracional, (consiste) no trabalho físico, emocional e mental necessário para a produção da população de forma socialmente organizada" (Arruzza, 2015, p. 55, grifos meus). É uma atividade que extrapola o mundo doméstico e que no capitalismo contemporâneo inclui práticas sociais que se dividem entre a família, o mercado e o Estado. $\mathrm{O}$ que se reproduz é a população, a vida e os sujeitos. Pensa-se para além da teoria geral da mobilização do exército industrial de reserva, como vimos em Saffioti, por exemplo. Nesse sentido, esforços teóricos de renovação do marxismo apontam para a direção de pensar uma teoria unitária e não dualista 
das relações entre produção e reprodução. A própria noção de classe social aparece renovada no sentido de que se incorpora a noção de que a classe se faz na conjunção entre produção e reprodução. ${ }^{5}$

Ainda segundo Kergoat (2016), são as tarefas do cuidado que melhor traduzem essa acepção reformulada do trabalho. A categoria "cuidado" ou "care" carece de uma definição exata. De acordo com Helena Hirata (2010, p. 48):

Se quiséssemos definir de maneira muito rigorosa o que é o care, seria: é o tipo de relação social que se dá tendo como objeto outra pessoa. Descascar batatas é care, mas de uma forma muito indireta: é care porque preserva a saúde, o outro ser. Fazer com que outro ser continue com saúde implica cozinhar, alimentá-lo, pois precisa desse cuidado material, físico. Então, pode-se dizer que tudo faz parte do care, mas aí não teríamos mais uma definição rigorosa de care.

Em que pese essa caracterização pouco precisa, alguns aspectos são considerados no entendimento do care: primeiro, é um trabalho que envolve afeto e intimidade, proximidade física e emocional, mediados pelo dinheiro; é um trabalho que relaciona pessoas dependentes, receptoras do cuidado, e pessoas que ofertam esse serviço e que estão em posições heterogêneas no mercado de trabalho, embora seja, em geral, uma atividade desvalorizada, feita por pessoas em situação precária de vida, sobretudo mulheres, pobres e migrantes. É um serviço em expansão, especialmente em uma sociedade em que as necessidades concretas de atividades de cuidado se ampliam devido ao crescente envelhecimento populacional. Por fim, é um trabalho que envolve algum tipo de agência, ${ }^{6}$ não podendo ser retratado como um

5. No interior do campo marxista, essa perspectiva não é incomum. Basta pensar nas contribuições de E. P. Thompson.

6. Agência é um conceito caro ao debate sociológico contemporâneo, pois nos permite pensar para além da dicotomia indivíduo X sociedade, marca do pensamento sociológico clássico. Agência diz respeito às formas de ação social que constituem a vida em sociedade. Toda ação social é ao mesmo tempo limitada e criadora, por isso a noção de que a dominação se constitui, mas não oblitera certas margens de manobra dos 
trabalho dominado per se; embora as condições de exploração desse trabalho sejam consideradas, observando-se as formas heterogêneas e pouco reguladas desse tipo de serviço. Resgatando o compromisso da abordagem das relações sociais de sexo com a lógica da contradição, as pesquisas costumam observar os antagonismos de raça, etnia, classe e gênero, conformando os trabalhadores e o trabalho do cuidado. Na produção contemporânea da sociologia do trabalho, o tema do cuidado ou care tornou-se central para pensar o estatuto do trabalho no capitalismo contemporâneo. As principais áreas de investigação abordaram recentes movimentos migratórios que despejam possíveis trabalhadores do cuidado (em sua maioria mulheres) entre fronteiras nacionais e dentro dessas fronteiras, inaugurando novos formatos de circulação da mão de obra feminina, mão de obra essa conformada por classe, raça e etnia (Guimarães, Hirata e Sugita, 2011).

\section{Interseccionalidade}

Até agora demos pouco destaque às relações étnico-raciais. Embora elas estejam incluídas nas reflexões das teóricas das relações sociais de sexo, é na perspectiva da interseccionalidade que a raça adquire evidência.

Não podemos falar de interseccionalidade sem situarmos o feminismo negro (Jabardo, 2012). Uma das contribuições centrais do feminismo negro foi questionar a universalidade do patriarcado como sistema de dominação. A reflexão sobre os limites da explicação patriarcal como forma universal de dominação das mulheres acompanhou os desdobramentos do feminismo dos anos 1970, e entre as feministas negras essa reflexão crítica atingiu uma considerável expressão teórica e política. A ideia de que o sistema patriarcal é uma forma de dominação dos corpos e da sexualidade das mulheres pelos homens e para proveito deles recebeu das feministas negras um

agentes, tornando a vida social, portanto, sempre mais complexa, nuançada e dinâmica. Compreender a ação dos agentes sociais nos permite entender como "habitamos as normas" (Mahmood, 2005). 
reparo fundamental: à pureza sexual imposta à mulher branca contrapõe-se a hipersexualização dos corpos das mulheres negras. À maternidade vigiada das mulheres brancas contrapõe-se a negação da maternidade das mulheres negras. O paradigma patriarcal projetou uma sombra sobre as experiências corporais e sexuais das mulheres negras, marginalizando-as como mulheres e reduzindo-as à sua raça. Esse ajuste de perspectiva para além da ótica patriarcal mudou o percurso do feminismo e ainda faz surtir seus efeitos no campo feminista atual. É a partir dele que a chamada interseccionalidade será construída. Não irei me aprofundar sobre o feminismo negro nesse artigo. Mas é importante sinalizar que o feminismo negro é o berço da interseccionalidade e que essa origem faz toda a diferença na forma como a interseccionalidade opera com raça.

A abordagem interseccional coloca a raça e a sexualidade no centro da problematização das relações de gênero. Mara Viveros (2009), no artigo "La sexualización de laraza y laracialización de lasexualidadenel contexto latino-americano actual", apresenta sucintamente autoras que trabalharam a articulação entre gênero, raça e sexualidade. Baseando-se nas discussões da feminista negra norte-americana Kimberle Crenshaw (2005, apud Viveros, 2009), primeira a usar o termo interseccionalidade, Mara Viveros aponta para a operação política de transformação do sexo, da sexualidade e da raça em natureza e que essa transformação justificou e justifica desigualdades, dificultando formas de resistência. Esse processo de transformação é histórico e está na base das estruturas de dominação que constituem a chamada modernidade colonial. Os sujeitos coloniais são marcados por sua cor e por seu gênero, esses se tornam a sua "essência" e os designam à posição de objeto da empresa moderna colonial. A empresa colonial, por sua vez, baseou-se amplamente no controle da sexualidade dos corpos colonizados, regulando os encontros sexuais legítimos e marginalizando os considerados ilegítimos. A historicidade desse processo é tratada em trabalhos destacados por Mara Viveros em seu artigo, como os estudos pioneiros de Verena Stolcke sobre casamento, classe e raça na Cuba do século XIX (1974, apud Viveros, 2009) e de Sueann Caulfield sobre honra, raça e moral sexual na construção da ideia de nação no Brasil republicano (1998, apud Viveros, 2009). A esses estudos 
acrescento o trabalho de Angela Davis (1981/2016), expoente do feminismo negro norte-americano. Em Mulheres, raça e classe, a autora percorre a situação dos negros e das negras no período pós-abolição da escravatura nos EUA, mostrando como se estabelecem desigualdades raciais profundas, clivadas por classe e gênero. No trabalho de Davis, alguns capítulos se dedicam a sexualidade e reprodução. No Brasil, Lélia Gonzalez (1984) é uma referência no assunto ao tratar da articulação entre racismo e sexismo. O que essas autoras nos apresentam é uma visão bastante inovadora a respeito da reformulação do debate de gênero a partir da ótica étnico-racial.

Refletindo a partir de (e nos) contextos de países colonizados, e amparando suas pesquisas em conjunturas históricas concretas, essas investigações trouxeram à tona a importância de se levar a sério o cruzamento de raça e gênero para a explicação das formas de subordinação e de resistência produzidas em sociedade. O corpo marcado por gênero, sexualidade e raça aparece como um distintivo fundamental para a constituição das situações de opressão. Obedecendo a um enfoque que preza pela situacionalidade do conhecimento, a perspectiva interseccional nos ajuda a compreender os sentidos da opressão em contextos delimitados, reservando um lugar essencial à raça e etnia por serem marcadores fundamentais na construção da chamada modernidade colonial. Nesse sentido, o corpo, seus significados e práticas têm um lugar central nas pesquisas de corte interseccional. Na abordagem interseccional, a raça funciona como experiência de constituição do eu e como criação de uma comunidade de sentidos e de destino interpelada pela cor. Essa concepção articula-se a sexualidade e gênero de uma forma constitutiva e inextrincável. ${ }^{7}$ Para compreendê-la, é absolutamente necessário trabalhar com a perspectiva dos sujeitos que vivem essas relações. Por isso, as situações de opressão, de marginalização, de fronteiras sociais são o terreno propício das investigações interseccionais. ${ }^{8}$ Não é à toa que

7. É possível inserir classe nesse contexto, desde que entendida como experiência de classe, no sentido thompsoniano (1987) ou como entendida por Pierre Bourdieu (1996).

8. Autoras ligadas à abordagem das relações sociais de sexo tendem a classificar a abordagem interseccional como descritiva, e não explicativa, pois esta não levaria em conta nem as dimensões materiais da 
a antropologia, entre as áreas das ciências sociais, é aquela mais próxima da perspectiva interseccional com seus estudos etnográficos que cruzam diferentes marcadores sociais (Moutinho, 2014).

Cabe apontar ainda que o que se denomina de modernidade colonial ou colonialidade é um processo moderno e permanente de desumanização que não se esgota em um passado colonial distante e superado. A colonialidade permite, incentiva e necessita da produção constante de classificações sociais que reduzem os seres humanos a objetos quantificáveis e controláveis. Categorizar, criar dicotomias e hierarquizar são atividades características da colonialidade. Para Lugones (2008 e 2014), a dicotomia central da modernidade colonial é a hierarquia dicotômica entre humano e não humano. O colonizado foi convertido em não humano no projeto colonial moderno. Nessa polarização entre humano e não humano, as gentes colonizadas opõem-se ao europeu branco e são inferiorizadas, racializadas e engendradas. A hipersexualização da fêmea heterossexual negra/indígena colonizada é um ícone desse processo. Ao engendrar, racializar e sexualizar, a colonialidade produz a diferença colonial como medida absoluta de todas as formas de vida, obscurecendo outras práticas e maneiras de existência. No entanto, faz parte dos processos de resistência à colonialidade a construção de subjetividades que escapam à desumanização. É necessário confrontar a diferença colonial a partir do pensamento do colonizado como ser que habita um lócus fraturado que está em constante tensão e conflito. Nesse sentido, a abordagem interseccional compromete-se em investigar as relações de opressão considerando fundamentalmente o ponto de vista daquele que se encontra marcado por essas relações. O poema "Gritaram-me negra", de Victoria Santa Cruz, expressa com maestria essa noção de situação de opressão e as resistências que se tecem a partir dela.

\footnotetext{
dominação nem a história (Hirata, 2014). No entanto, essa crítica carece de uma compreensão mais fina sobre o entendimento da noção de "situação de opressão". A questão tem a ver com metodologia de pesquisa e de construção do objeto de investigação. O recorte analítico da abordagem interseccional é a delimitação da situação e os distintos atores sociais em interação nessa situação. Há história, mas não no sentido dado pelo materialismo. Não se considera a expropriação e a exploração de classe como pensadas pela abordagem marxista clássica. Mas se considera classe a partir de outras visões, como indica a nota citada.
} 
$[\ldots]$

E odiei meus cabelos e meus lábios grossos

E mirei apenada minha carne tostada

E retrocedi

Negra!

[...]

Até que um dia que retrocedia, retrocedia e ia cair

Negra! Negra! Negra! Negra!

[...]

E daí? E daí?

Negra!

Negra!

Sim!

Negra!

SOU!

A riqueza da abordagem interseccional, coerente com suas raízes no feminismo negro, pode ser traduzida pelas palavras de Patricia Hill Collins (2016, p. 101):

Sociólogos podem se beneficiar ao considerarem seriamente a emergência da literatura multidisciplinar que denomino pensamento feminista negro, precisamente porque para muitas mulheres intelectuais afro-americanas a marginalidade tem sido um estímulo à criatividade. Como outsiders within, estudiosas feministas negras podem pertencer a um dos vários distintos grupos de intelectuais marginais cujos pontos de vista prometem enriquecer o discurso sociológico contemporâneo. Trazer esse grupo para o centro das análises [...] pode revelar aspectos da realidade obscurecidos por abordagens mais ortodoxas.

\section{Considerações finais}

Percorremos um caminho que aponta para três distintas abordagens teóricas e metodológicas sobre gênero. Essas abordagens estão presentes 
na produção acadêmica do Serviço Social; algumas com mais forte presença, como as duas primeiras. O objetivo deste artigo foi sistematizar essas concepções e apontar alguns aspectos que considero importantes: 1) É preciso discernir cada uma das abordagens para que o diálogo entre elas seja de fato profícuo. É fundamental saber para onde cada uma nos leva teoricamente para que não façamos um uso inadequado delas; 2) As críticas aos limites e potencialidades de cada abordagem podem e devem ser feitas, desde que se guarde a devida atenção ao que cada uma de fato afirma e que se conheça de onde vieram e para onde apontam; 3) Abordagens teóricas e metodológicas não são receitas, mas inspiração para fazer pesquisa. Sempre que elas nos inspiram, são suficientes; se nos limitam à repetição do que já sabemos, não nos servem.

Nesse breve inventário produzido até aqui persistem algumas lacunas para o Serviço Social: gênero tem sido usualmente pensado como sinônimo de mulheres. Em geral, é a situação das mulheres que aparece com mais nitidez nas abordagens sobre gênero empregadas na área. Os homens aparecem menos e quando o fazem é por derivação. Os homens se fazem conhecer a partir da investigação sobre mulheres. As pesquisas acabam enfocando a questão da mulher ou das mulheres e menos as relações de gênero propriamente ditas. Não é por acaso que inúmeras vezes o interesse pelo conceito de patriarcado é o que desponta nos estudos do Serviço Social, fazendo com que se perca o foco na discussão de gênero.

A atenção ao gênero para além das formas binárias é menos evidente nas pesquisas do Serviço Social. Embora alguns estudos já tratem dos temas das sexualidades e corpos dissidentes, a discussão ainda é restrita. A contribuição da teoria queer ao debate de gênero encontra pouca acolhida nas produções acadêmicas do Serviço Social.

O cruzamento entre raça e gênero, tal qual formulado pela abordagem interseccional, ainda é periférico na produção do Serviço Social. A tendência à incorporação da questão étnico-racial tem sido feita pela via da relação com o debate marxista clássico, em que raça tende a aparecer como forma de estratificação social — o mesmo se passa com gênero —, e assim coadjutora 
das relações de exploração de classe, ou através da abordagem das relações sociais de sexo, incluindo raça como consubstancial à classe e gênero e, portanto, estruturante da vida social. No entanto, essa incorporação, seja num caso como no outro, precisa ser tratada com mais atenção, pois há o risco de raça ser lida como sinônimo de cor (negro), e não como sinônimo de relações raciais, relações entre negros e brancos, num processo similar ao que já ocorre com o debate de gênero. O compromisso em pensar as relações de sexo, de classe e de raça como inerentemente antagônicas, embora seja frutífero, também pode levar à excessiva redução dessas relações a esquemas dicotômicos, deixando de fora aspectos mais complexos dessas mesmas relações, sobretudo as de gênero e de raça. Além disso, pensar raça como categoria sociológica também necessita de maior explicitação. Essa explicitação, por sua vez, precisa de um aprofundamento sobre a história das relações raciais no Brasil recente.

\section{Recebido em 5/1/18 - Aprovado em 26/2/18}

\section{Referências bibliográficas}

ARRUZZA, C. Considerações sobre gênero: reabrindo o debate sobre patriarcado e/ou capitalismo. Outubro Revista, 23, p. 35-58, jan. 2015.

COLLINS, P. H. Aprendendo com a outsider within: a significação sociológica do pensamento feminista negro. Sociedade e Estado, Brasília, v. 31, n. 1, p. 99-127, jan./abr. 2016.

DAVIS, A. Mulheres, raça e classe. São Paulo: Boitempo, 2016.

ENGELS, F. A origem da familia, da propriedade privada e do Estado. Rio de Janeiro: Bestbolso, 2014.

FRASER, N. O feminismo, o capitalismo e a astúcia da história. Mediações, Londrina, v. 14, n. 2, p. 11-33, jul./dez. 2009. 
FRIEDAN, B. A mística feminina. Petrópolis: Vozes, 1971.

GONZALEZ, L. Racismo e sexismo na cultura brasileira. Ciências Sociais Hoje, São Paulo, p. 223-244, 1984.

GUIMARÃES, N. A.; HIRATA, H. S.; SUGITA, K. Cuidado e cuidadoras: o trabalho de care no Brasil, França e Japão. Sociologia e Antropologia, Rio de Janeiro, v. 1, n. 1, p. 151-180, 2011.

HIRATA, H. S. Teorias e práticas do care: estado sucinto da arte, dados de pesquisa e pontos em debate. In: FARIA, N.; MORENO, R. (Orgs.). Cuidado, trabalho e autonomia das mulheres. São Paulo: SOF, 2010. p. 42-56.

. Gênero, raça e classe: interseccionalidade e consubstancialidade das relações sociais. Tempo Social, São Paulo, v. 26, n. 1, p. 61-73, jun. 2014.

; KERGOAT, D. Novas configurações da divisão sexual do trabalho. Cadernos de Pesquisa, São Paulo, v. 31, n. 132, p. 595-609, set./dez. 2007.

HOLMSTROM, N. Como Karl Marx pode contribuir para a compreensão do gênero? In: CHABAUD-RYCHTER, D. et al. (Orgs.). O gênero nas ciências sociais. Brasília: EdUNB, 2014. p. 343-358.

JABARDO, M. (Org.). Feminismos negros: una antología. Madri: Traficantes de Sueños, 2012.

KERGOAT, D. O cuidado e a imbricação das relações sociais. In: ABREU, A. R. P.; HIRATA, H.; LOMBARDI, M. R. (Orgs.). Gênero e trabalho no Brasil e na França: perspectivas interseccionais. São Paulo: Boitempo, 2016.

LUGONES, M. Colonialidad y gênero. Tabula Rasa, Bogotá, v. 76, n. 9, p. 73-101, jul.-dez. 2008.

. Rumo a um feminismo descolonial. Estudos Feministas, Florianópolis, v. 22, n.3, p. 935-952, set.-dez. 2014.

MAHMOOD, S. Politics of piety: the islamic revival and the feminist subject. Princeton: Princeton University Press, 2005.

MOUTINHO, L. Diferenças e desigualdades negociadas: raça, sexualidade e gênero em produções acadêmicas recentes. Cadernos Pagu, Campinas, n. 42, p. 201-248, 2014.

SAFFIOTI, H. Gênero, patriarcado e violência. São Paulo: Fundação Perseu Abramo, 2004. 
SAFFIOTI, H. A mulher na sociedade de classes: mito e realidade. São Paulo: Expressão Popular, 2013.

SCOTT, J. Usos e abusos do gênero. Projeto História, São Paulo, n. 45, p. 327-351, dez. 2012.

SOUZA-LOBO, E. A classe operária tem dois sexos: trabalho, dominação e resistência. São Paulo: Fundação Perseu Abramo, 2011.

THOMPSON, E. P. A formação da classe operária inglesa. Rio de Janeiro: Paz e Terra, 1987. v. 1.

TRAT, J. Friedrich Engels: da propriedade privada à sujeição das mulheres. In: CHABAUD-RYCHTER, D. et al. (Orgs.). O gênero nas ciências sociais. Brasília: EdUNB, 2014. p. 359-372.

VIVEROS, M. La sexualización de la raza y la racialización de la sexualidad en el contexto latinoamericano actual. Universidad de Caldas, 2009. Disponível em: $<$ http:// www.ucaldas.edu.co/docs/seminario_familia/Ponencia_MARA_VIVEROS.pdf $>$. Acesso em: 28 dez. 2017. 